\title{
Analysis and Design of Hybrid CCM Boost DC-DC Converter for High Voltage Gain
}

\author{
A.Thiyagarajan ${ }^{1 *}$, Dr.S.Chitra ${ }^{2}$, K.Sivakumar ${ }^{3}$ \\ ${ }^{1 *}$ Assistant Professor, Dept. of EEE, Karpagam Institute of Technology, Coimbatore. \\ ${ }^{2}$ Assistant Professor, Dept. of EEE, Government College of Technology, Coimbatore. \\ ${ }^{3}$ Assistant Professor, Dept. of ECE, Sri Ranganathar Institute of Engineering and Technology, Coimbatore.
}

\begin{abstract}
Recently, DC-DC converters with high voltage gain are usually required in battery powered applications like renewable energy system, fuel cells, uninterrupted power supply and automotive application. These applications demand high step-up voltage gain, efficiency and reduced switching losses. Some classical converter with magnetic coupling can easily achieve high step-up voltage gain. The power transformer volume is a problem for the development of the compact converter. The energy of the transformer leakage inductance can produce high voltage stress, increases the switching losses and reducing the converter efficiency.In this work, a hybrid topology combines coupled inductor and voltage multiplier cell is proposed to provide high voltage gain. Coupled inductor boost converter is used to reduce the volume of the isolation transformer and provide the required high voltage gain, but with penalty of high voltage, current stress and high duty cycle operation. In voltage multiplier cell based dc-dc converter, the required voltage gain is obtained by adding required number of multiplier cells consisting of capacitors and diodes. The proposed hybrid converter is used to avoid the extreme duty ratios, high voltage stress, and large switching losses. The proposed hybrid converter is simulated and the results are obtained using MATLAB/Simulink software.
\end{abstract}

Keywords: Boost dc-dc converter, Literature survey, Coupled inductor boost converter, Voltage Multiplier cells.

\section{Introduction}

Continuous-Conduction-Mode (CCM) boost converters have been widely used as the front-end converter for active input current shaping. Recently the demand for DC-DC converters with high voltage gain are usually required in battery powered applications like renewable energy system, fuel cells, embedded system, uninterrupted power supply (UPS) and automotive applications. These applications demand high step-up static gain, high efficiency and high power density. Hence, it is preferable for the high voltage boost converters to possess high voltage gain (more than 10), high efficiency and high power density[14]. The step-up function, the demands such as low current ripple, high efficiency, fast dynamics and high power density have also increased for various applications. In applications that require a voltage step-up function and a continuous input current[11], a CCM boost converter is often used due to its advantages such as continuous input current and simple structure.

*Corresponding Author: e-mail: thiyagueeegct@gmail.com, ISSN 2320-7590

(C) 2018 Darshan Institute of Engg. \& Tech., All rights reserved
However, it has a limited voltage gain due to its parasitic components. Moreover, the reverse-recovery problem of the output diode degrades the system's performances. At the moment when the switch turns on, the reverse-recovery phenomenon of the output diode of the boost converter is provoked. The switch is submitted to a high current change rate and a high peak of reverse-recovery current. The parasitic inductance that exists in the current loop causes a ringing of the parasitic voltage, and then, it increases the voltage stresses of the switch and the output diode. These effects significantly contribute to increase switching losses and electromagnetic interference. The reverse-recovery problem of the output diodes is another important factor in $\mathrm{dc} / \mathrm{dc}$ converters with high voltage gain.

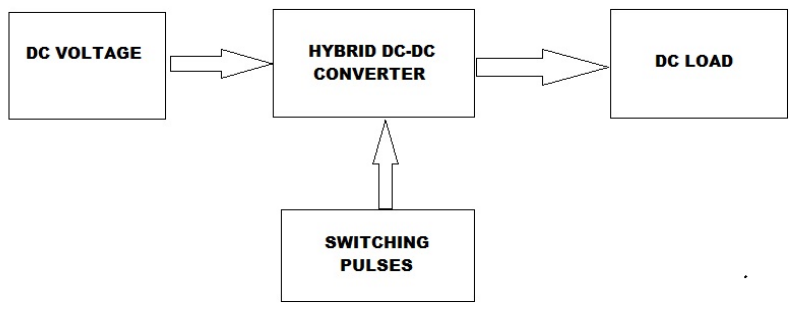

Figure 1. Block diagram of Hybrid Boost DC-DC Converter for High Voltage gain 
The fig. 1 shows the Block diagram of Hybrid Boost DCDC Converter.In this paper, Literature survey of various previous researchers is presented in part II. Third Chapter describes about Simulation of Coupled Inductor Boost Dc-Dc Converter. Design of of Voltage Multiplier Cell Based Boost Converter is presented in Part IV. Simulation of of Voltage Multiplier Cell Based Boost Converter is presented in Part V.Design and Simulation of Proposed Boost Converter is presented in Part VI and VII. This Paper proposes a new softswitched CCM boost converter suitable for high-power applications such as power factor correction, hybrid electric vehicles, and fuel cell power conversion systems.

\section{Literature Survey}

The step-up stage normally is the critical point for the design of high efficiency converters due to the operation with high input current and high output voltage, thus a careful study must be done in order to define the topology for a high step-up application. In the previous researches, various boost converter topologies have been proposed to obtain high voltage gain. A brief note of some of the works has been presented here.

Qun Zhao et al proposed a high step-up dc-dc converters that do not require isolation and it can provide high step-up voltage gain, but with the penalty of either an extreme duty ratio or a large amount of circulating energy. DC-DC converters with coupled inductors can provide high voltage gain, but their efficiency is degraded by the losses associated with leakage inductors[1].

Converters with active clamps recycle the leakage energy at the price of increasing topology complexity. High efficiency is achieved because the leakage energy is recycled and the output rectifier reverse-recovery problem is alleviated.

Qiong $M$ et al detailed analysis the design issues of the active-clamp forward converter circuit with peak current mode control in small signal stability and large-signal transients are discussed. A design procedure is provided to solve circuit issues under these conditions. It is the first time that with the aid of simulation, we are able to optimize the circuit design of the active-clamp forward converter for largesignal transient behaviours[3].

F. C. Lee et al discussed the DC-DC converters with coupled inductors can provide high voltage gain, but their efficiency is degraded by the losses associated with leakage inductors. Converters with active clamps recycle the leakage energy at the price of increasing topology complexity. A family of high-efficiency, a high step-up dc-dc converter with simple topologies is proposed in this paper. The proposed converters, which use diodes and coupled windings instead of active switches to realize functions similar to those of active clamps, perform better than their active-clamp counterparts. High efficiency is achieved because the leakage energy is recycled and the output rectifier reverse-recovery problem is alleviated[2].

R.J. Wai and R.Y. Duan used a high magnetising current charge the primary winding of the coupled inductor, and the clamped capacitor is discharged to the auxiliary capacitor when the switch is turned on. In contrast, the magnetising current flows continuously to boost the voltage in the secondary winding of the coupled inductor, and the voltages across the secondary winding of the coupled inductor, the clamped capacitor and the auxiliary capacitor are connected in series to charge the output circuit. Thus, the related voltage gain is higher than in conventional converter[6]

Rong-Jong Wai et al presented the topology, a threewinding coupled inductor is used for providing a high voltage gain without extreme switch duty cycle and enhancing the utility rate of magnetic core. Moreover, the energy in the leakage inductor is released directly to the output terminal for avoiding the phenomenon of circulating current and the production of switch surge voltage[6].

In addition, the delay time formed with the cross of primary and secondary currents of the coupled inductor is manipulated to alleviate the reverse-recovery current of the output diode. It can achieve the aim of high-efficiency power conversion.

Chung-You Lin et al discussed proposed a high-efficiency dc-dc converter with high voltage gain and reduced switch stress. In this proposed topology, a three-winding coupled inductor is used for providing a high voltage gain without extreme switch duty cycle and enhancing the utility rate of magnetic core. Moreover, the energy in the leakage inductor is released directly[7] to the output terminal for avoiding the phenomenon of circulating current and the production of switch surge voltage. The utilization of a coupled inductor is useful for raising the step-up ratio of the conventional boost converter.

Araujo, S.V. et al reported a non-isolated DC-DC converter with high voltage gain using a three-state switching cell and voltage multiplier stages based on capacitors. The value of the gain can be modified depending on the requirements of the application by means of the number of multiplier stages and the duty cycle[8].

This converter employing the three-state switching cell, the size of the inductor is reduced because the operating frequency of the inductor is double of the switching frequency. 
Marcos Prudente et al presented the use of the voltage multiplier technique applied to the classical non-isolated dcdc converters in order to obtain high step-up static gain, reduction of the maximum switch voltage, zero current switching turn-on. The diodes reverse recovery current problem is minimized and the voltage multiplier also operates as a regenerative clamping circuit, reducing the problems with layout and the EMI generation. These characteristics allows the operation with high static again and high efficiency, making possible to design a compact circuit for applications where the isolation is not required.

Hyun-Lark Do detailed a soft-switching dc/dc converter with high voltage gain. It provides a continuous input current and high voltage gain. Moreover, soft-switching characteristic of the proposed converter reduces switching loss of active power switches and raises the conversion efficiency[9].

The reverse-recovery problem of output rectifiers is also alleviated by controlling the current changing rates of diodes with the use of the leakage inductance of a coupled inductor.

Sungsik Park and Sewan Choi proposed a new softswitched continuous conduction- mode (CCM) boost converter suitable for high-power applications such as power factor correction, hybrid electric vehicles, and fuel cell power conversion systems. The proposed converter achieves zerovoltage-switched (ZVS) turn-on of active switches in CCM and zero-current-switched turn-off of diodes leading to negligible reverse-recovery loss.

The components' voltage ratings and energy volumes of passive components of the proposed converter are greatly reduced compared to the conventional zero-voltage-transition converter. Voltage conversion ratio is almost doubled compared to the conventional boost converter[10].

R. Huang and S. K. Mazumder presented a soft-switching mechanism based on zero-voltage-zero-current-switching (ZVZCS) principle for the front-end isolated DC/DC converter of an isolated three-phase rectifier-type highfrequency-link bidirectional power converter.

In conjunction with a back-end DC/AC converter operating with a novel patent-filed hybrid modulation scheme outlined in , , and that reduces the number of hard-switched commutation per switching cycle, the proposed ZVZCS scheme can lead to less overall switching losses than other conventional switching schemes.

The proposed ZVZCS scheme is effective for various load conditions, operates seamlessly with a simple active-clamp circuit, and is suitable for applications where low-voltage dc to high-voltage three-phase ac power conversion is required[12].

\section{Simulation of Coupled Inductor Boost Dc-Dc Converter}

The simulation model of coupled inductor boost converter is shown figure 2. The converter is designed with input voltage of $24 \mathrm{~V}$ and the switching frequency is $50 \mathrm{kHz}$. The DC output voltage obtained from the converter is $240 \mathrm{~V}$.

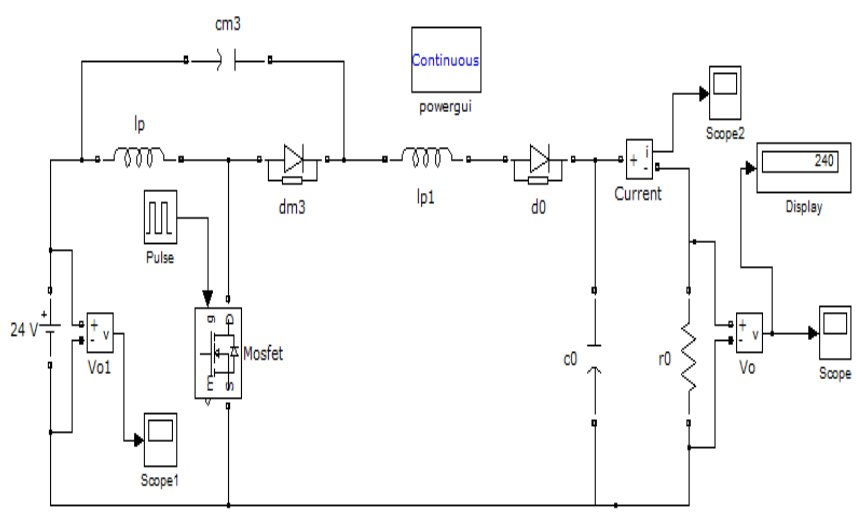

Figure 2.Simulation model of coupled inductor boost converter

MOSFET is used as a controllable switch which is used in the converter bridge. The following figure 3 shows the input voltage, output voltage and output current waveforms of coupled inductor boost converter. The proposed converter is able to provide a wide range of step-up voltage gains using various turn`s ratios for the coupled inductor.

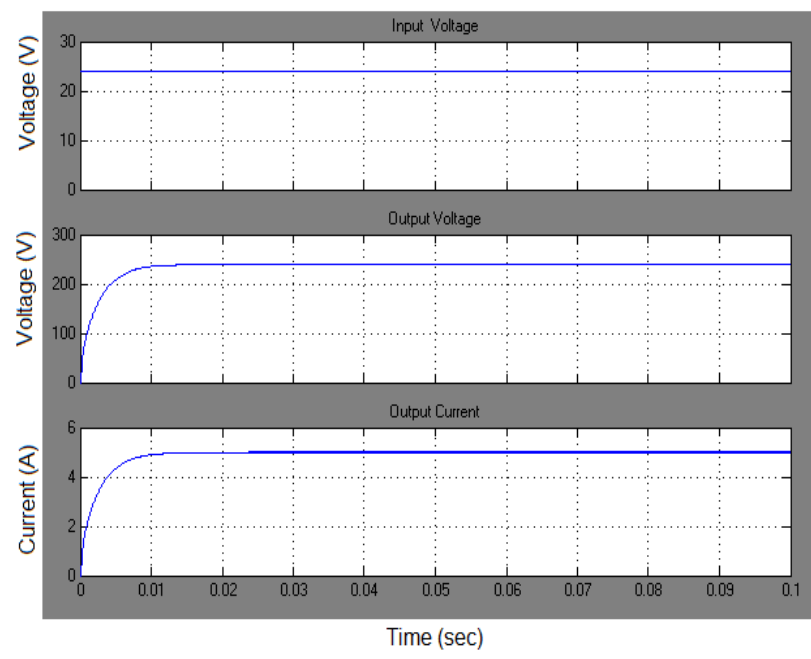

Figure 3. Output voltage waveform of Coupled Inductor Boost converter 
The voltage gain can be greatly heightened due to the utilization of a coupled inductor with a lower turn`s ratio. The switch voltage stress is not related to the input voltage. The diode short-circuits and reverse-recovery problems can be solved because of all the diodes possessing voltage clamped properties. This high-efficiency converter topology provides designers with an alternative choice to convert renewable energy efficiently, and it also can be extended easily to other power conversion systems for satisfying high-voltage demands. The high step up voltage gain, but with penalty of high voltage, current stress and high duty cycle operations. The soft switching techniques are not able to achieve in this topology. In this case the leakage inductance of the coupled inductor can induce high voltage stress and also degrades the efficiency.

\section{Simulation OF Voltage Multiplier Cell Based Boost Converter}

The voltage multiplier cell based converter is designed by considering the following specifications.

- Input Voltage: $12 \mathrm{~V}$.

- Output Voltage: $100 \mathrm{~V}$.

- Output power: $100 \mathrm{~W}$.

- Switching Frequency: $50 \mathrm{kHz}$.

- Number of multiplier stages: $\mathrm{M}=1$

4.1 Static Gain: The multiplier capacitor is charged with the output voltage of the classical boost converter at the fourth operation stage.

$$
\mathrm{V}_{0}=\mathrm{V}_{\mathrm{CM} 2}+\mathrm{V}_{\mathrm{in}} \frac{1}{\left(1-\mathrm{D}_{)}\right)}
$$

As this capacitor is connected in series with the converter output at the transference of the energy stored in the input Inductance, the output capacitor is charged with the boost output voltage multiplied by two.

$$
V_{\mathrm{CM} 1}=V_{\mathrm{CM} 2}=V_{\mathrm{in}} \frac{1}{(1-D)}
$$

Thus, the static gain of the proposed converter, operating in continuous conduction mode is presented in

$$
\mathrm{q}=\frac{\mathrm{v}_{\mathrm{o}}}{\mathrm{v}_{\mathrm{in}}}=\frac{(\mathrm{M}+1)}{1-\mathrm{D}}
$$

Where, M- Number of multiplier stages, D- Duty cycle

4.2 Switch Duty-Cycle: The nominal duty-cycle is defined by

$$
\mathrm{D}=\frac{\mathrm{V}_{\mathrm{a}}-\mathrm{V}_{\mathrm{in}}(\mathrm{M}+1)}{\mathrm{V}_{\mathrm{o}}}
$$

4.3 Switch Voltage: The maximum voltage in all diodes and power switch is equal to the voltage that is equal to the output voltage of the classical boost, calculated by (2). The voltage in all components is half of the output voltage.

$$
\mathrm{V}_{\mathrm{CM} 1}=\mathrm{V}_{\mathrm{s}}=\mathrm{V}_{\mathrm{CM} 2}=\mathrm{V}_{\mathrm{in}} \frac{1}{(1-\mathrm{D})}
$$

4.4 Input Inductance: The design of the input inductance is the same of the classical boost converter. Considering a current ripple equal to $45 \%$ of the nominal input current, the input inductance is equal to

$$
\begin{aligned}
& \Delta \mathrm{I}_{\mathrm{L}}=\frac{\mathrm{P}_{\mathrm{o}}}{V_{\text {in }}} \cdot 0.45 \\
& \mathrm{~L}_{\text {in }}=\frac{V_{\text {in }} \mathrm{D}}{\Delta \mathrm{I}_{\mathrm{L}} \mathrm{f}}
\end{aligned}
$$

4.5 Voltage Multiplier Capacitor: The minimum capacitance of the voltage multiplier capacitor depends of the maximum output power, the multiplier capacitor voltage and the switching frequency. The maximum output power considered in this example is equal to $150 \mathrm{~W}$ for a nominal output power equal to $100 \mathrm{~W}$

$$
\mathrm{C}_{\mathrm{MI} 1} \geq \frac{\mathrm{P}_{\text {omax }}}{\mathrm{V}^{2} \mathrm{CM1} \cdot \mathrm{f}}
$$

Where, f- Switching frequency, $\mathrm{V}_{\mathrm{CM} 1}-$ Voltage of the CM1 multiplier capacitor and $\mathrm{P}_{\text {omax }}$ - Maximum output power.

It is possible to add more multiplier cells in order to achieve higher step-up ratios. The reduction of the reverse recovery current of all diodes is obtained with only one resonant inductor in the first voltage multiplier cell.

\section{Simulation OF Voltage Multiplier Cell Based Boost Converter}

The simulation model of voltage multiplier cell based boost converter is shown figure 4. MOSFET is used as a controllable switch which is used in the converter bridge. A $12 \mathrm{~V} \mathrm{DC}$ source has been used in the model. The converter produce the output voltage of $100 \mathrm{~V}$. MOSFET is used as a controllable switch which is used in the converter bridge. The switching frequency of the converter switch is $500 \mathrm{kHz}$.

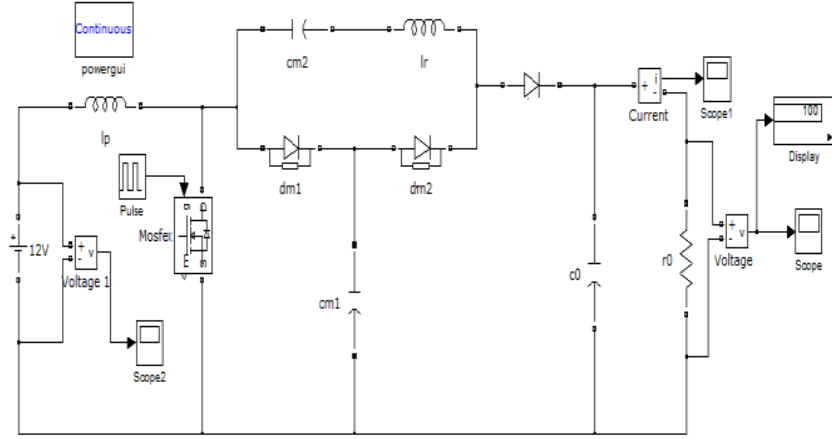

Figure 4. Simulation model of voltage multiplier cell based boost converter 
The following figure 5 shows the input voltage, output voltage and output current waveforms of coupled inductor boost converter. From the waveform it is clear that the converter able to give high voltage gain.

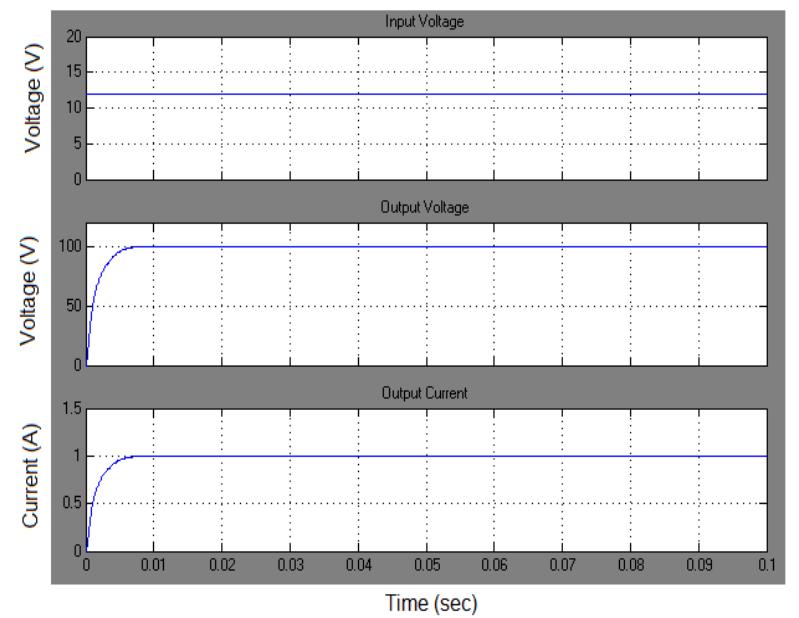

Figure 5. Input voltage, Output voltage and Output current waveform of voltage multiplier cell based boost converter.

The voltage multiplier cell increases the static gain of the classical boost by a factor $(\mathrm{M}+1)$, where $\mathrm{M}$ is the number of multiplier cells. However, the maximum switch voltage $(\mathrm{M}+1)$, is lower than the output voltage. It can provide high static gain operation without the use of power transformer, allowing a reduction of the weight and volume that are important parameters for compact portable applications.

\section{Design of Proposed Boost Converter}

MATLAB simulation model of the proposed boost converter is shown fig.6. The input DC voltage is 24 Volt fed from the battery source. The output voltage and output power is $240 \mathrm{~V}, 1.2 \mathrm{~kW}$ respectively. The switching frequency is 500 $\mathrm{kHz}$. The voltage gain is obtained separately for clamp mode coupled inductor topology and voltage multiplier cell. The calculated equivalent resistance Ro for the required for the required load specification is $75 \mathrm{ohm}$. The voltage gain for clamp-mode coupled inductor topology as shown in equation below.

$$
\begin{gathered}
\frac{V_{\circ}}{V_{i}}=\frac{d}{1-d} *(N+1) * \frac{(1+K)}{2} \\
\frac{V_{o}}{V_{\text {in }}}=\left(\frac{M+1}{1-D}\right)
\end{gathered}
$$

For a duty cycle (d) of 0.7 and turns ratio $(\mathrm{N})$ of 5 , voltage gain is obtained by above equation and is found to be 14 . The voltage gain for voltage multiplier cell is shown in equation
For a duty cycle (D) of 0.7 and multiplier cell (M) considered as 1 , voltage gain is obtained by using above equation and is found to be 7 .

The proposed hybrid converter is used to obtain high stepup static gain, high efficiency and high power density. Hence, it is preferable for the high voltage boost converters to possess high voltage gain and high efficiency. The converter follows soft switching technique and operates in CCM mode and is thus suited for high voltage applications. The theoretical analysis is verified by a $1.2 \mathrm{~kW}$ system with 24 to $240 \mathrm{~V}$ conversions.

\section{Simulation of Proposed Hybrid Boost Converter}

Simulation is done using Matlab and the results are presented in this chapter. The proposed hybrid boost converter is shown in figure 6 . The simulation model was generated using MATLAB Simulink. A specification detail of proposed hybrid boost converter is shown in below.

- Input Voltage - $24 \mathrm{~V}$

- Output Voltage - $240 \mathrm{~V}$

- Output Power- $1.2 \mathrm{KW}$

- Switching Frequency $-500 \mathrm{kHz}$

- Capacitance - Cc \& Co- $2.2 \mu \mathrm{F} \& 220 \mu \mathrm{F}$

- Capacitance - CM1 \& CM2- $3.3 \mu \mathrm{F}$

- Inductance- Lp \& Ls- $15 \mu \mathrm{H} \& 45 \mu \mathrm{H}$

A $24 \mathrm{~V}$ DC source has been used in the model. A series Rload of $75 \Omega$ is used. The converter combines coupled inductor and voltage multiplier cell which is used to produce the output voltage of $240 \mathrm{~V}$. MOSFET is used as a controllable switch which is used in the converter bridge. The switching frequency of the converter switch is $500 \mathrm{kHz}$. The DC input voltage is shown in figure 7. Driving pulses of the MOSFET are shown in figure 8. The output voltage waveform of the proposed hybrid boost converter is shown in figure 9. Figure 10. Shows the output current waveform.

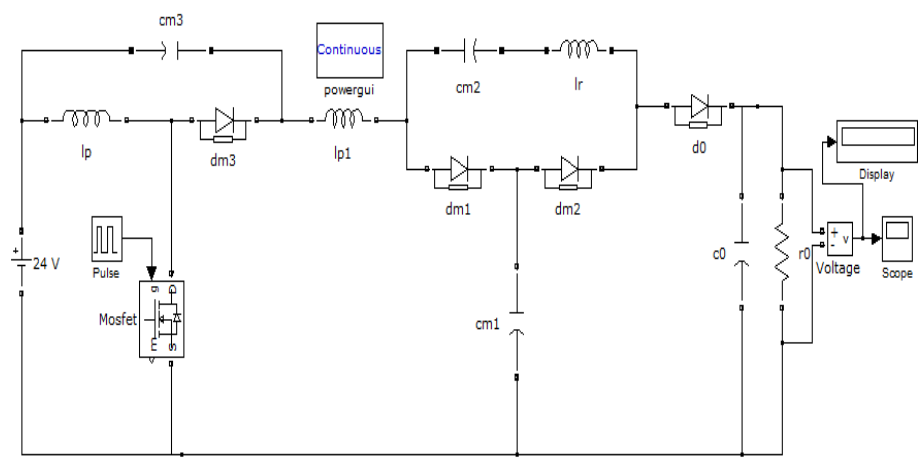

Figure 6. Simulation model of proposed hybrid boost converter with R-load 


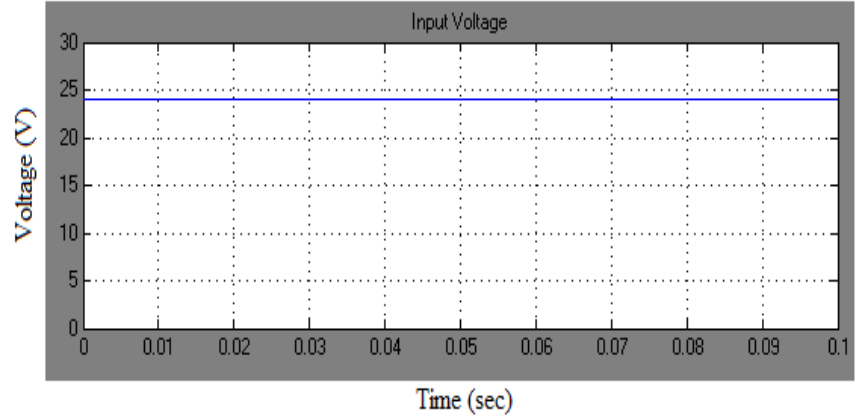

Figure 7. Input voltage waveform of Proposed DC-DC Converter

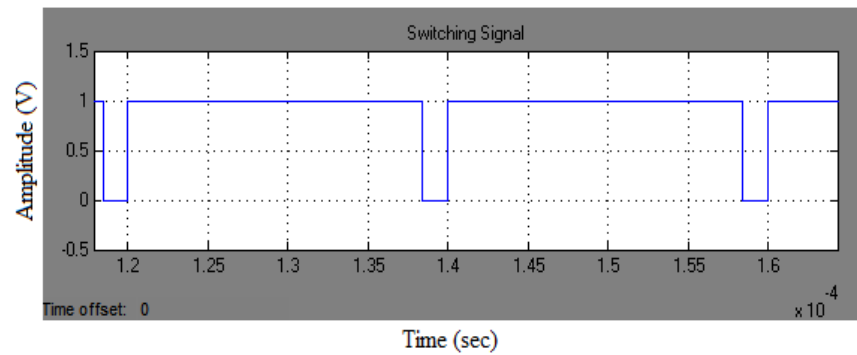

Figure 8. Gate pulse waveform of Proposed DC-DC Converter

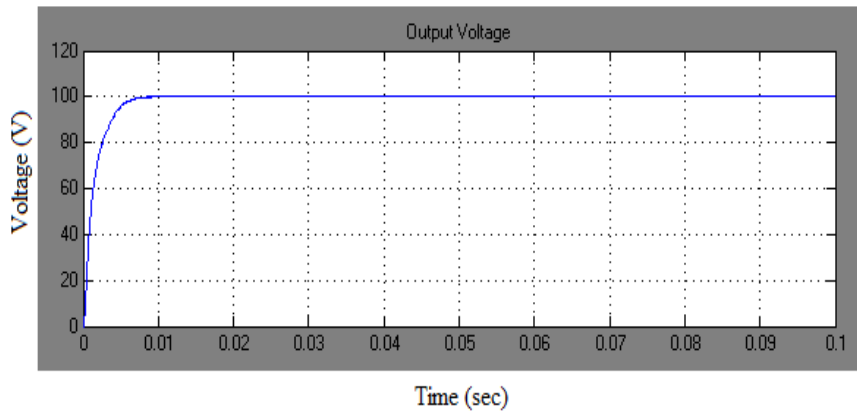

Figure 9. Output voltage waveform of Proposed DC-DC Converter

The proposed hybrid converter is used to obtain high stepup static gain, high efficiency and high power density. Hence, it is preferable for the high voltage boost converters to possess high voltage gain and high efficiency.

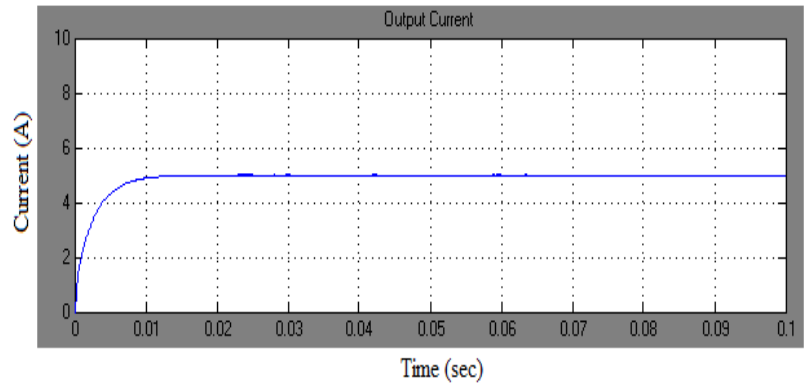

Figure 10. Output current waveform of Proposed DC-DC Converter
The average output voltage was $240 \mathrm{~V}$ under this condition. It can be observed that soft turn off has been obtained. In addition, the maximum switch stress is around 50 volts. This is advantageous as the device needs to be rated for a lower voltage though the output voltage is quite high.

Table 1. Comparative Performance parameters measured by simulation results of the Converters.

\begin{tabular}{|c|c|c|c|c|c|}
\hline Type & Vin & Vo & Po & Fs & D \\
\hline $\begin{array}{c}\text { Voltage } \\
\text { Multipier } \\
\text { based } \\
\text { Boost }\end{array}$ & $12 \mathrm{~V}$ & $100 \mathrm{~V}$ & $100 \mathrm{~W}$ & $50 \mathrm{KHz}$ & 0.45 \\
Converter & & & & & \\
\hline $\begin{array}{c}\text { Proposed } \\
\text { Hybrid } \\
\text { Boost } \\
\text { Converter }\end{array}$ & $24 \mathrm{~V}$ & $240 \mathrm{~V}$ & $1200 \mathrm{~W}$ & $500 \mathrm{KHz}$ & 0.85 \\
\hline
\end{tabular}

\section{Conclusion}

The proposed converter can minimize the voltage stresses of the switching devices and lower the turn ratio of the coupled inductor. It provides a continuous input current, and the ripple components of the input current can be controlled by using the inductance of the CCM boost cell. Soft switching of power switches and the alleviated reverserecovery problem of the output rectifiers improve the overall efficiency.

The proposed hybrid boost converter topology is expected to provide high voltage gain, high efficiency and high power density overcoming the above mentioned drawbacks and hence would be suitable for automotive application. The performance of hybrid boost converter is analysed. Thus the hybrid boost converter is capable of improving the voltage level from $24 \mathrm{~V}$ to the required level. Simulation results are presented for a $1.2 \mathrm{~kW}, 500 \mathrm{kHz}$ DC - DC converter.

\section{References}

1. Q. Zhao, P. Xu, and F. C. Lee, 2001, "A simple and effective method to alleviate the rectifier reverserecovery problem in continuous-current-mode boost converters," IEEE Transactions on Power Electronics, Vol. 16, No. 5, pp. 649-658.

2. Q. Li, Lee, F. C and Jovanovic, M. M., 2002, "Large-signal transient analysis of forward converter with active-clamp reset," IEEE Transactions on Power Electronics., Vol. 17, pp. 15-24.

3. Q. Zhao and F. C. Lee, 2003, "High-efficiency, high step-up dc-dc converters," IEEE Transactions on Power Electronics, Vol. 18, No. 1, pp. 65-73.

4. Qiong M. Li, and Fred C. Lee, 2005, “ Design consideration of the Active- clamp forward converter with current mode during large signal 
transient", IEEE Transactions on Power Electronics, Vol. 152, No. 1, pp. 65-73.

5. R.J. Wai, C. Lin and Y. Chang, 2007, "Highefficiency dc-dc converter with high voltage gain and reduced switch stress," IEEE Transactions on Power Electronics, Vol. 54, No.1, pp. 793-805.

6. Rong-Jong Wai, and Rou-Young Duan, 2008, “ High step-up converter with coupled inductor", IEEE Transactions on Power Electronics, Vol. 20, No. 5, pp. 1025-1035.

7. Cheng-Tao Tsai and Chih-Lung Shen, 2008 "Interleaved Soft-Switching Buck Converter with Coupled Inductors", IEEE Transactions on Power Electronics, Vol. 21, No.8, pp.877-882.

8. Araujo, S.V., Bascope, R.P and T. Menezes, 2009, "High step-up converter with high voltage gain employing three state switching cell and voltage multiplier" in Proceedings of PESC, pp. 2271-2277.

9. Hyun-Lark Do, 2010, "A soft-switching DC-DC converter with High voltage gain", IEEE Transactions on Power Electronics, Vol. 25, No. 5, pp.1193-1200.
10. Sungsik park and Sewan Choi, 2010 " A High efficiency high step-up DC-DC converter ", IEEE Transactions on Power Electronics, Vol.25, No. 5, pp.1201-1211.

11. Y.-C. Hsieh, T.-C. Hsueh, and H.-C. Yen, 2009, “An interleaved boost converter with zero-voltage transition," IEEE Transactions on Power Electronics, Vol. 24, No. 4, pp. 973-978.

12. R. Huang and S. K. Mazumder, 2009, "A softswitching scheme for an isolated DC/DC converter with pulsating DC output for a three-phase high frequency- link PWM converter," IEEE Transactions on Power Electronics, vol. 24, no. 10, pp. 2276-2288.

13. N. Mohan, T. M. Undeland and W. P. Robbins., 1995, "Power Electronics: Converters, Applications and Design", 2nd ed., New York: John Wiley \& Sons, Inc, pp. 177-178.

14. R. W.Robert W. Erickson and D.Dragan Maksimovic, 2000, "Fundamentals of Power Electronics", 2nd edition. Boston, MA: Kluwer. 